\title{
CV co-occurrence and articulatory control in three Brazilian children from 0:06 to 1:07.
}

\section{Mariana Hungria*, Eleonora C Albano}

\begin{abstract}
Many studies in language acquisition have addressed consonant/vowel co-occurrence, henceforth CV. Traditional views focus on the upper vocal tract (Davis, B.L., MacNeilage, P.F., 1995; Browman, C., Goldstein, L., 1992), while a recent one stresses the importance of its lower end (Esling, J., 2012). None has nevertheless attempted to understand how these two tracts interact and cooperate in early vocalization. Besides, the role of the ambient language in this interaction is also understudied. Although there are common preferences for certain CV combinations, sensitivity to language environment may already be present in babbling (Boisson-de-Bardies, B.; Vihman, M., 1991).The aim of this project was to integrate such apparently contradictory views by reporting on research that observed activity in both ends of the vocal tract during the emergence of $\mathrm{CV}$ combinations in three Brazilian children acquiring Brazilian Portuguese in interaction with their parents, between the ages of 0:06 and 1:07.
\end{abstract}

\section{Key words:}

Buccalization, CV co-occurrence, Laryngeals.

\section{Introduction}

The literature on the acquisition of phonology reports stable preferences for the combination of certain consonants and vowels in babbling and first words in a variety of languages. This project aimed at observing how three Brazilian children acquire control over buccal and the laryngeal articulation, by collecting data of spontaneous speech interaction with their parents. The study focused on three major perspectives found in the literature: Content/Frame theory, Articulatory Phonology and the Laryngeal Constrictor Model.

\section{Results and Discussion}

We used a mixed design, whereby one child was followed longitudinally while the other two were observed crosssectionally at later, complementary stages. Data were collected using a digital recorder, transcribed with the aid of acoustic analysis, and later processed with a syllable counter.

Table 1 displays longitudinal data for $\mathrm{P} 1$ at 0:06-0:07. Regarding buccal consonants, $\mathrm{P} 1$ seems to prefer coronals and dorsals. As for vowels, P1's front vowels were the majority while back vowels were the minority.

Table 1. P1's raw CV's combination count (0:06-0:07)

\begin{tabular}{lcccc}
\hline & \multicolumn{2}{c}{$\mathbf{V}$} & & $\mathbf{N}$ \\
\cline { 2 - 5 } & front & back & central & \\
\hline $\mathbf{C}$ labial & 14 & 6 & 31 & 51 \\
\cline { 2 - 5 } coronal & 58 & 6 & 185 & 249 \\
\hline dorsal & 35 & 3 & 15 & 53 \\
\hline \multicolumn{1}{c}{ laryngeal } & 43 & 12 & 280 & 335 \\
\hline Total & 150 & 27 & 511 & 688 \\
\hline
\end{tabular}

By way of example, Table 2 shows cross-sectional data for P3 at 1:05-1:07. Bearing in mind that he was observed at a later stage, P3 seems to have followed a different path towards buccalization, favoring labials. Central vowel combinations are massive, followed by back and front vowels. There is still an expressive number of combinations involving laryngeals past twelve months.
Table 2. P2's raw CV's combination count (1:05-1:07)

\begin{tabular}{llcccc}
\hline & \multicolumn{2}{c}{$\mathbf{V}$} & & $\mathbf{N}$ \\
\cline { 2 - 5 } & front & back & central & \\
\hline C labial & 0 & 10 & 58 & 68 \\
\cline { 2 - 5 } coronal & 3 & 46 & 1 & 50 \\
\hline dorsal & 3 & 0 & 0 & 3 \\
\cline { 2 - 5 } laryngeal & 12 & 38 & 19 & 69 \\
\hline Total & 18 & 30 & 142 & 190
\end{tabular}

Overall, our results uncovered the following trends: i) biomechanical constraints interact with ambient language influences; ii) control over articulations seems to be different for vowels and consonants; iii) infants tend to have a favorite babbling vowel; iv) the lower vocal tract remains active past 12 months; v) not all children acquire articulatory control in the same way.

\section{Conclusions}

In sum, our data do not support any specific view, but, rather, call for the integration of several separate strands in the literature. In addition, they point to the need for a thorough study of the sounds of child-adult interaction, considering details of adult expressive vocalization that might elucidate the role of the environment in children's early preference for laryngeals.

\section{Acknowledgement}

We thank CNPq and PIBIC Unicamp for the financial support.

Boisson-de-Bardies, B.; Vihman, M. Adaptation to Language: Evidence from Babbling and First Words in Four Languages. Language, 1991, Vol. 67, No. 2, pp. 297-319.

Browman, C.; Goldstein, L. Articulatory Phonology: An Overview. Phonetica, 1992, 49, p. 155-180.

Davis, B., MacNeilage, P. The Articulatory Basis for Babbling. Journal of Speech and Hearing Research, 1995, 38(6), p.1199-1211.

Esling, J. The Articulatory Function of the Larynx and the Origins of Speech. Proceedings of the Annual Meeting of the Berkeley Linguistics Society, 2012, 38. 